\title{
Process design for social empowerment under the inequitable phenomenon of conurbation: new links between Academia and communities
}

DOI: $10.20396 /$ labore.v13i0.8653134

Submetido 08 jul. 2018.

Aceito 19 dez. 2018.

Publicado 03 jul. 2019.

\author{
Juan Manuel Lozano de Poo \\ < https://orcid.org/0000-0002-4700-440X> \\ Universidad Autónoma de San Luis Potosí / San Luis Potosí [México]
}

María Elena Molina Ayala

$<$ https://orcid.org/0000-0002-6322-7654> Universidad Autónoma de San Luis Potosí / San Luis Potosí [México]

\section{ABSTRACT}

This study aims to improve the welfare of local rurban communities by reducing their vulnerability, thereby empowering them through new strategic partnerships with Academia in order to address the inequitable phenomenon of conurbation, and reappraise the rurban landscape as a cultural capital. The willingness to meet specific demands from members of rurban localities is the driving force for creating an inclusive design process, which consists of three areas: the local community, as well as students and researchers from the Faculty interacting assertively with and in such a context. The design process is focused on providing viable options for communities to relate the physical and social structure systems that make up the habitat to the objective of leveraging their capacity for resilience, as well as strengthening their identity. The creation of new links between Academia and communities at-risk encourages the participation of the three areas that make up the design process. Through communities' experience and cultural capital, a dialogue can be instated between the uncertainty and empowerment of the parties involved. Coexistence between rural and urban landscapes requires a system and structure, which actively promotes the preservation of natural resources and social cohesion. The task of each of the participants encounters its true meaning when practical actions arising from and for the adaptation of the local cultural landscape become a reality. How does one begin if not by opening a dialogue between researchers and student members of vulnerable communities?

\section{KEYWORDS}

Design process. Inequitable conurbation. Cultural capital. 


\section{Background}

There is a myth, sometimes widespread, that a person needs only to do inner work... that a man is entirely responsible for his own problems; and that to cure himself, he needs only to change himself... The fact is, a person is so formed by his surroundings, that his state of harmony depends entirely on his harmony with his surroundings (Christopher Alexander, 1979).

One of the main concerns of urban and landscape design in San Luis Potosí is the way in which rural communities integrate to the urban dynamic and sprawl. The unequal growth, due to personal interests set the bases and rules for the communities to change their way of life and activities in order to meet the new demands and mixture of ground uses and migration. We define this particular way of constructing citizenship as an imbalanced one. The core of the landscape of these communities is changing dramatically by the way urban elements impose on the vulnerable context.

This phenomenon is a common concern, so it found its place in the new restructuration of the Faculty of the Habitat of the Autonomous University of San Luis Potosí. The new vision contemplates, as a part of its structure, interdisciplinary work among students and teachers adding a third element, the community. The main difference between the traditional view and ours is the methodological strategies used specially for incorporating the real social concerns brought directly by university students that form an active role of the communities involved in order for them to be resilient under these circumstances.

New forms of learning how society comes together in public spaces require innovative processes that enable students to set within a university environment that promotes diverse approaches to interdisciplinary sociospatial resolution of problems. This is the subject exposed, along with the vision and restructuration of the Faculty of the Habitat of the Autonomous University of San Luis Potosi, through a flexible institutional model that plays a major role in the attention to the demands made by society. Here relays the importance of opening the possibilities to new methodologies and processes that foster the creative dimension of communities to stimulate teachers and students from the reflection, creation and realization dimensions, to endorse dynamism in the curricular, educational, academic and pedagogical models. The challenges faced by universities in the knowledge society, represent an encouraging scene for educational institutions as they regain a new sense of credibility in society.

We created a new, complex unity that was much larger than what was defined by the boundary line of our allocated site because we allowed the existing context to radiate inward. Compare this modernism, which is blind and insensitive to context, a kind of monotonous imposition notes Schumacher (2013). We seek to develop new strategic partnerships between each actor in the new model, knowing beforehand their role and assuming the social responsibility required. The empowerment generated through the gestation of knowledge, building and reconfiguring different bonds among academia, community and students is one that aims to diminish the inequitable phenomenon of conurbation. Together, the three areas that integrate the proposal configure new and creative paths to preserve and minimize vulnerability.

This process design is centered to meet social demands, so it starts by promoting participation and work on real problems born from the urbanization process. The site was chosen strategically, in a locality that represents a viable model to apply the method. It is common to find communities within conurbation process; such is the case for the one selected, which in addition has historical and patrimonial sites. La Sauceda, a former hacienda is located in the municipality of Villa de Zaragoza of the state of San Luis Potosi in México, it is considered to be under urban sprawling.

How can communities at-risk preserve their identity while dealing with legibility loss generated by massive horizontal urbanization?

It seems like the city will keep on growing and expanding, guided by particular interests, with no social structure or established patterns that could determine and settle the dialogue between rural and urban landscapes. The main objective of this investigation is to promote social consciousness and participation among all the parties involved, one of the most critical steps of the strategy planned is the involvement of students who are members of the susceptible community. This is the way in which real concerns and solutions can materialize in a design process and finally in a viable project. We all know society has a long way to go but time is catching up, even as we speak land is being bought for such individual purposes, the remains of cultural and natural resources are being permanently damaged or in this case, stolen. The urbanization process needs to be reflected on, structured, well planned and carefully materialized, each time aiming for social cohesion. 


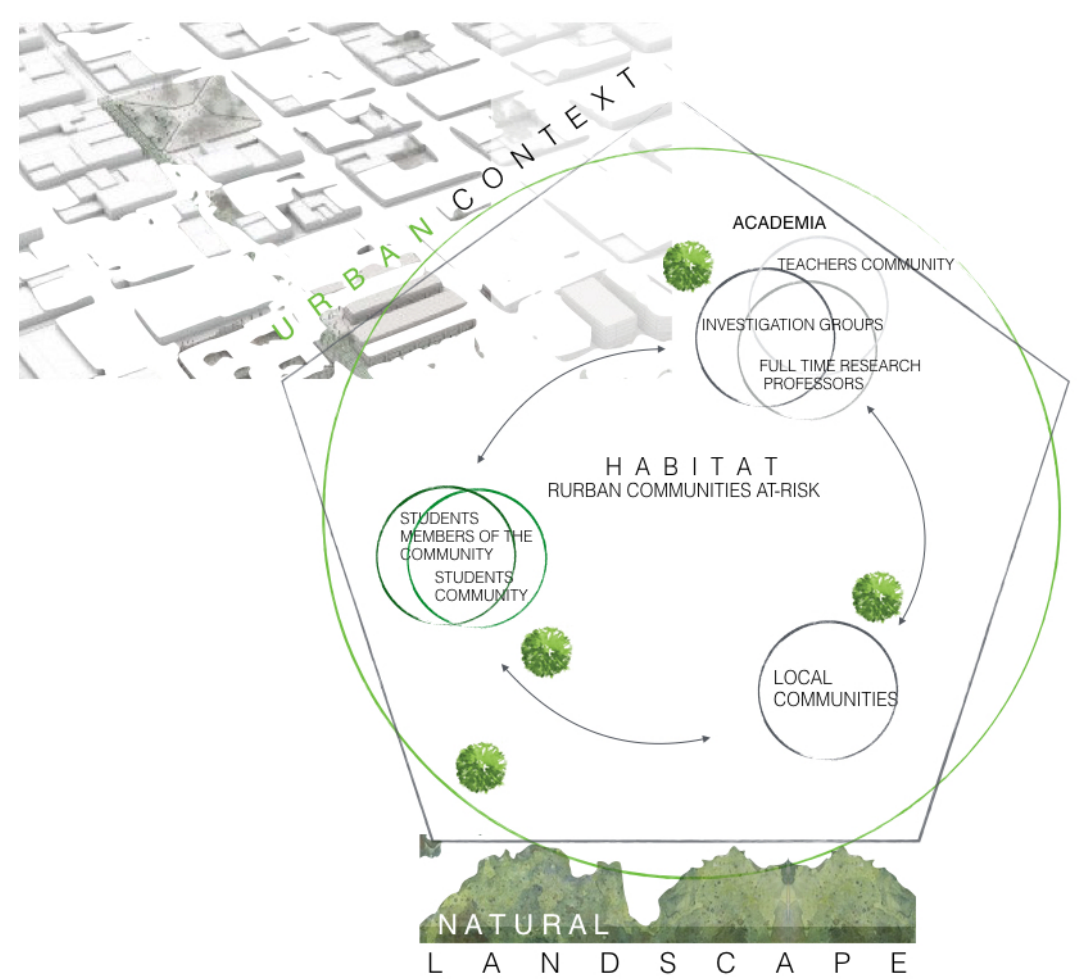

Figure 1. Process design strategy. Source: Juan Manuel Lozano de Poo.

Coexistence between rural and urban landscapes requires understanding them as systems; such coexistence needs a conceptual structure for its well-planned growth, which actively promotes the preservation of natural resources. Teamwork within communities of practice is vital for identifying the task and role of each of the participants, only then will they encounter their true value when practical actions arising from and for the adaptation of the local cultural landscape become a reality. How does one begin if not by opening a dialogue between researchers and student members of vulnerable communities?

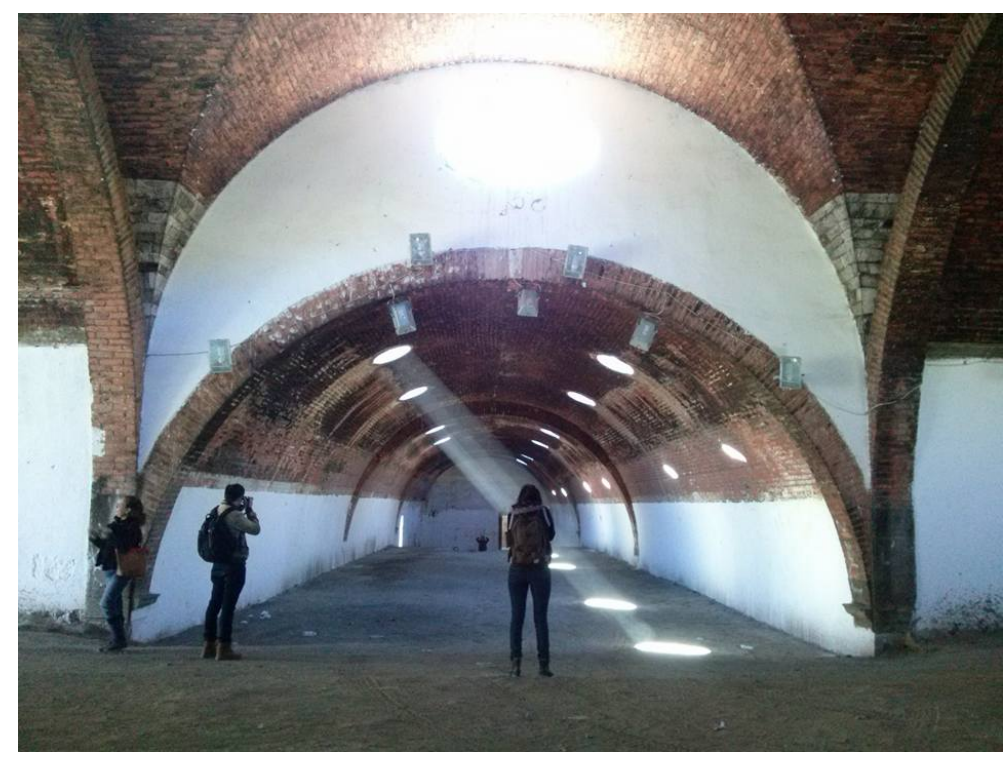

Figure 2. La Sauceda former hacienda. Source: Maria Elena Molina Ayala.

Therefore, the exercise inside the interdisciplinary workshop origins from the development of the critic notions of the problems that are to be attended, as we have exposed, problems detected and born from social concern, circumscribed in the preoccupying phenomenon of unequal conurbation. Knowing how to problematize is thus, one of the central tasks of the occupations of the researcher that has to be carefully transmitted into the teaching of scientific research. Definitely an expertise that characterizes the skilled investigator, a set of strategies, abilities and practical skills, not just because they are on the edge of the road where creativity begins, but by the discipline and perseverance that its learning requires, according to Sánchez (2010). 


\section{The institutional model enphasized on interdisciplinary practice}

There is no point in teaching a liberal arts and sciences curriculum that continues to fragment knowledge and creates specialists who cannot communicate across disciplinary lines. Education must focus on the trunk of the tree of knowledge, revealing the ways in which the branches, twigs, and leaves all emerge from a common core, notes Root-Bernstein (1999).

First, we are to set the bases of how education is considered nowadays in order to understand the actual context of urban and landscape design through an interdisciplinary practice centerd in a social approach of intervening the habitat.

Educational institutions currently have a great amount of credibility, especially in Latin America, because it has a high personal economic return, product of the investment in education. This process design is in addition, within this context, thought to meet social demands through the role of universities. We encourage the constant renewal of our institutions in order to return consistent answers based on the credibility that society itself has granted.

The context has and will continue to change in the society of knowledge and information, schemes have shifted and the role of urban and landscape design schools in this globalized world must be reinterpreted under postures governed by the deep understanding of the current problems and opportunities it represents. Education is once again a major productive source creating new socio-economic paradigms where the main challenges begin when recognizing the importance of learning new skills and strategic urban/regional planning methods by the three parties, students, researchers and members of the community. Our universities should encourage reflection and practice, inspiring creativity and enriching the will of the community, urging the right decisions based on the liability and comprehensive understanding of the multiplicity of realities. The goal is to propose conscious interventions of the cultural landscape. How to start the debate if not by questioning the level of commitment of government institutions, universities and students to perform the above?

Within the Faculty of Habitat of the Autonomous University of San Luis Potosi, promotion and creation of a joint vision of interdisciplinary work is being constructed, based on the concept of an institution that has to provide innovative proposals and alternative solutions, which determine different paths for multiple processes of adaptation and appropriation of public space on equal bases. It is a job that includes the six disciplines of the Faculty of the Habitat, involving actively the community of researchers, teachers and students in order to act collectively through the field of design to implement projects through joint exercises.

The new proposal for the institutional model of the Faculty of the Habitat integrates the following four dimensions:

- Curricular: (centrality on the student) it represents a flexible mapping of contents, setting the ground for interdisciplinary sharing. Vertical and transversal procedures are synthesized at workshops. If we understand that the teacher is the one who designs the curriculum, his first task is to identify its relevant issues. Then analyse the central themes of political and cultural context of daily debate $[\ldots]$ he will study the possibilities of connecting the curricular subject with the current concerns. It is not to apply the contents of a text but to assemble, disassemble and reassemble the curriculum [...] assuming autonomous and responsible decisions (Litwin, 2008).

Figure 3. Students, community members and researchers in La Sauceda. Source: María Elena Molina Ayala.

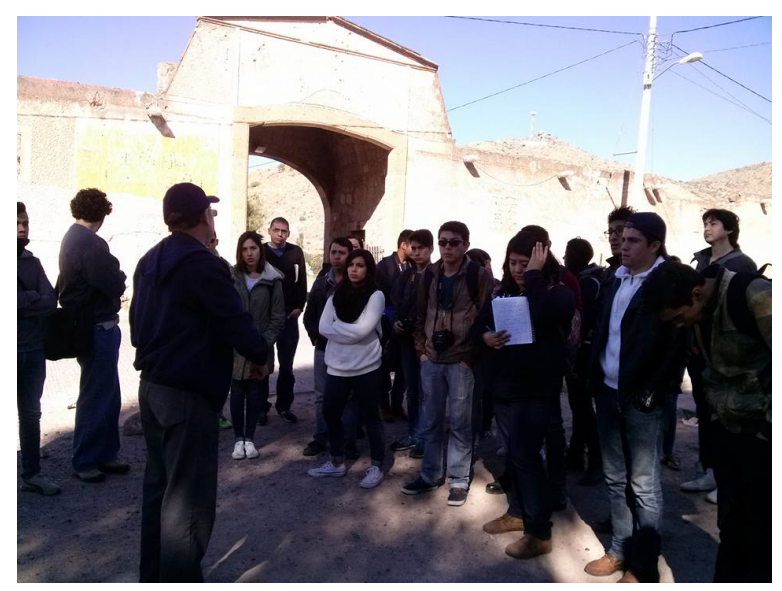


- Academic: (Structure of the Faculty of the Habitat, knowledge and practices of and for the habitat) this dimension provides the academic structure required for knowledge to convert itself into a dynamic and practical approach to intervene the habitat. This structure is based on the premise and importance of the bound between research, creativity and materialization in the comprehension of the habitat. The student and teacher communities represent the willingness of a socially concerned well-structured model. Besides contributing to the success of organizations in world markets, these communities have another benefit. In the globalizing knowledge economy, companies are not just competing for market share. They are also competing for talent-for people with the expertise and capabilities to generate and implement innovative ideas, according to Wenger (2002).

- Pedagogical: (being able, knowing how and why) this dimension focuses its attention on the students' competency development. We include new visions and proposals from problem based learning and project-based learning. The invariable purpose of education was, is, and will always remain, on preparing these young people for life. A life according to the reality in which they are intended to enter. To be prepared, they need instruction, "practical, concrete and immediately applicable knowledge," to use the expression of Tullio De Mauro. In addition, to be "practical", quality education needs to promote and propagate the openness of mind, not his stubbornness, notes Bauman (2007).

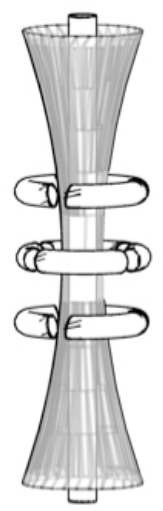

Habitat, the core:

- Reflection

- Creation

- Materialization

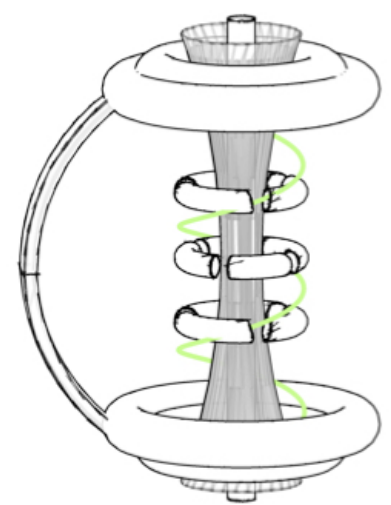

Interdisciplinary relations:

- Full-time research professors

- Investigation groups

- Students groups

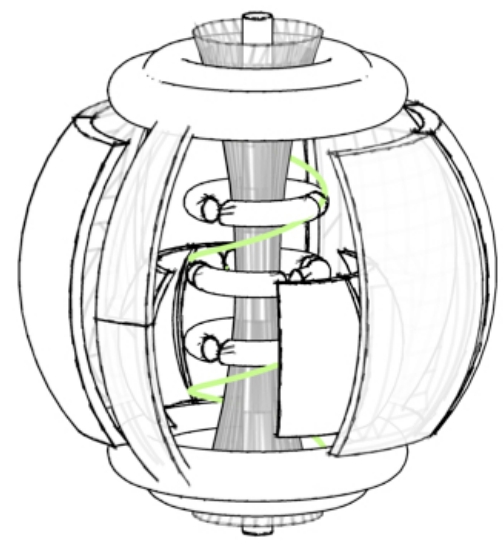

Dynamic institutional model:

- Interdisciplinary workshops

- Synthesis through project design

Figure 4. Institutional model first draft. Source: Juan Manuel Lozano de Poo.

- Educational: (integral formation, comprehensive training, being, knowing and doing) the formation of the student must consider and promote teamwork, constructive dialog between communities and students, reflection in action and social cohesion. The integral formation of students includes values and ethics that constitute their beings, how they learn and acquire knowledge, and finally, how to apply knowledge for social benefit. Knowledge is not static. It is continually in motion. In fact, our collective knowledge of any field is changing at an accelerating rate. What was true yesterday must be adapted to accommodate new factors, new data, new inventions, and new problems. This dynamism does not mean that a domain of knowledge lacks a stable core, according to Wenger (2002).

Together, along with the right learning attitude and self-commitment of students and researchers, the four dimensions solidly construct the basic core and foundations for inter and transdisciplinary work. Present in all cases, in the continuous and creative process of design where the conformation of communities of practice take place through common goals and shared interests. 


\section{Labor \& Engenho}

\section{Communities of practice in urban and landscape design}

Knowledge has become the key to success. It is simply too valuable a resource to be left to chance. Companies need to understand precisely what knowledge will give them a competitive advantage. They then need to keep this knowledge on the cutting edge, deploy it, leverage it in operations, and spread it across the organization. Without communities focused on critical areas, it is difficult to keep up with the rapid pace of change, notes Wenger (2002).

In the second part of this investigation, we come to establish new links between first drafts of the institutional model of the Faculty of the Habitat and building solid communities of practice for our knowledge field. Domain, practice and community, each represent as put by Etienne Wenger, essential aspects that compose these sort of communities.

So this is how both approaches entwine, on the one hand we have the complete model that provides the constitutional bases and structure for new practitioners, on the other hand, the domain of the urban and landscape discipline, which is in constant change and renovation. Both encounter diverse difficulties and challenges along the way; nevertheless, they are to be addressed by teamwork and a culture of community integration.

The concept of communities of practice first and original use came from learning theories; and it applies to almost every field, that is the reason why we found such potential in the integration of diverse communities of practice as a strategy for bonding academic efforts with the at-risk communities' problems and concerns. It works both ways; each concept either applies to the researchers or to the community members, the link for them to assemble as one, is to unite the students throughout an interdisciplinary project.

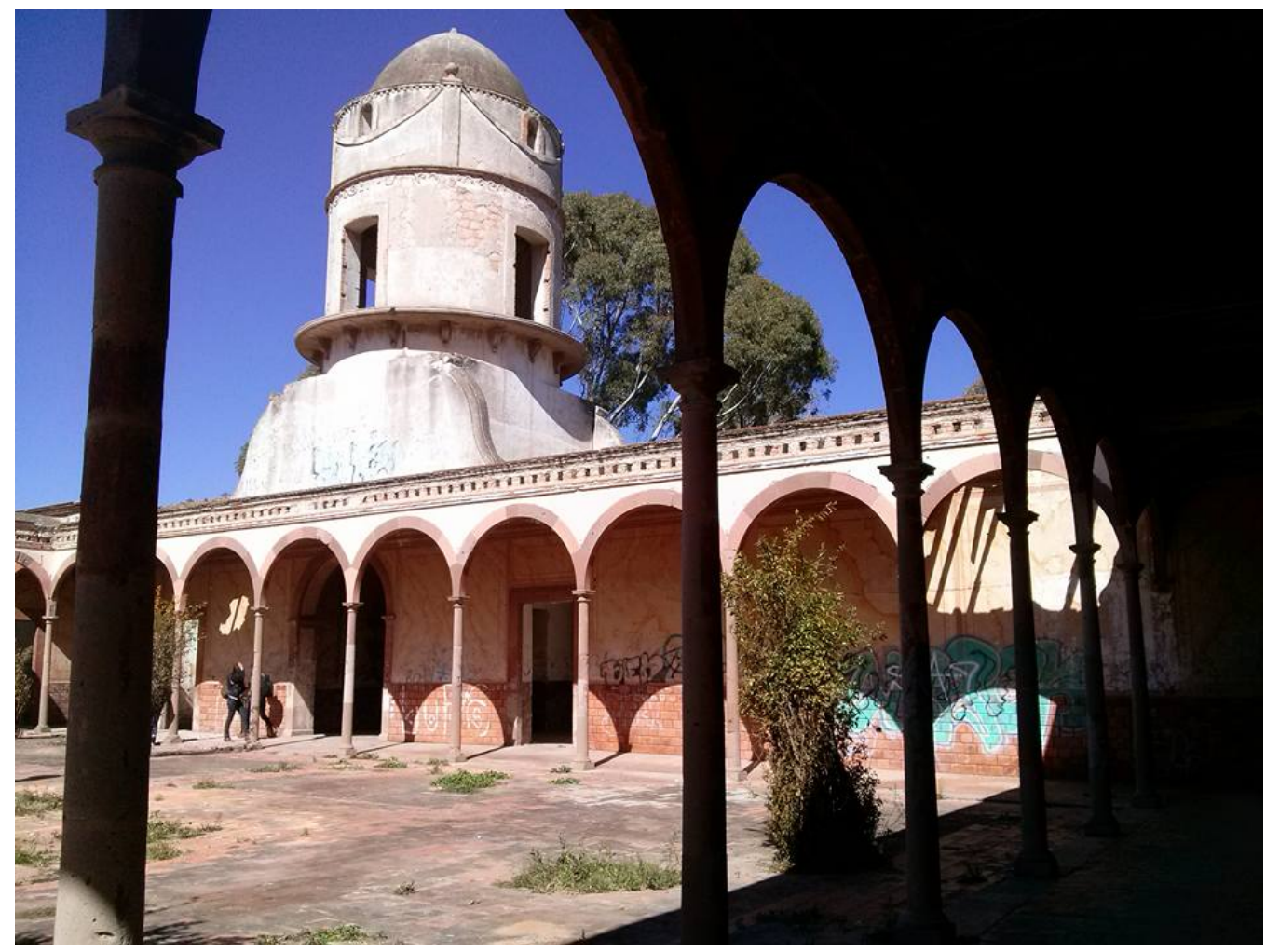

Figure 5. Centre patio of La Sauceda. Source: María Elena Molina Ayala.

The next three steps are set out to be a preparation phase and part of the process itself. As a first step, the preliminary incorporation of knowledge and its domain from all the parties involved in the same vessel, so to speak, is necessary for the integral conception and the problematize process while building up identity. Secondly, the generation of communities by empathizing, sharing experiences and setting common goals, is needed in the pursuit of knowledge, done by well-planned activities, discussions and interaction that allow members to learn together. Finally, practice is required as a key element for embarking on the process that follows. It is done by sharing and getting to define the resources to be used as common tools by the community of practice. For practical means, this investigation and exercise underlines the practice dimension and adds it to the pedagogical sphere of the institutional model. 


\section{Process design for social empowerment and resilience}

Tools for thinking in a creative way, provide a common language for students in different fields, they promote the dialog through experience and knowledge, setting the grown for discovering new creative links between their activities aiming a common goal (Root-Bernstein, R \& M., 1999).

Now that we have discussed the actual context of education and its role in society; how the structure provided by the new institutional model of the Faculty of the Habitat that emerged from its own restructure is a tool for resilience; and the importance of building communities of practice; under this third heading, we present the process design for social empowerment.

The process design is based, among others, on interdisciplinary practice notes Morin (2011), which is one of the competences developed by students along the curriculum, understanding it as a flexible one. This course is to be formally installed one year and a half from now, but for it to work, we are exercising through pilot programs. This is one of the first examples and the results have been improving time after time.

The Interdisciplinary Program allows a real possibility for cooperation between the six different disciplines of the Faculty of the Habitat, generating an interdependence between them and its intention is that the student, fortifying the acquired knowledge, develops an interdisciplinary vision for innovative solutions through a complex and integral project. This way, students, researchers, teachers and community members can identify strengths and weaknesses of its discipline and domain to incorporate experiences in a new way of working, where ones learn from each other and from the dialogue, analysis, criticism and agreements that lead to the execution of creative proposals.

Reflection, creation and materialization are the three basic guidelines that structure complex and integral thought. Required each, to construct different and specific elements of the whole. Understood as stages, they interact back and ford in a revolving manner. If in one point of the process, elements are fragmented, the main objective is to put them back together in a creative and innovative way. This exercise is repeated as long as required so that synthesis, as a creative tool, can lead the paths into which the project becomes a real and tangible proposal for the community's needs.

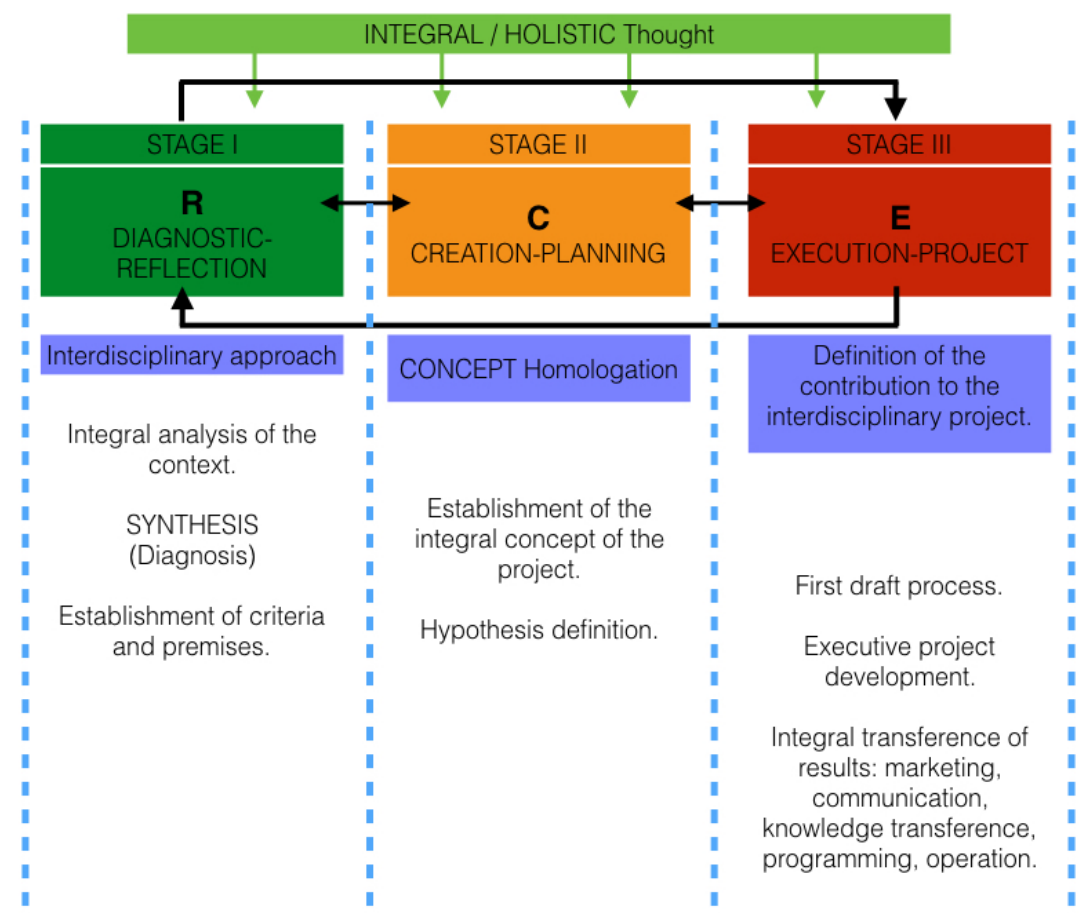

Figure 6. Process design stages. Source: Faculty of the Habitat. Autonomous University of San Luis Potosi.

The general objective of the workshop is to develop interdisciplinary thought and work, so the students thought evolve to resolve complex and fundamental problems from the perception of knowledge fields of the Habitat, through an integral project, which methodological perspective promotes intercommunication and mutual enrichment of those who participate. 
The program is divided in three units, each integrate diverse stages and bond between them, it is important to underline that they are design to be adaptable to different situations and approaches. These are the particular objectives for each unit:

- Unit 1: Identify qualities and fundamental characteristics of the phenomenon, demands and needs with a sense of social responsibility for the creation of an assertive diagnosis throughout emphasis on teamwork and collaborative work.

- Unit 2: Create a conceptual basis with elements of materiality, expression and specific criteria of a formal intervention on the prefiguration of an integral project.

- Unit 3: Formalize the content, processes and evaluation of the integral intervention of a draft or executive project, its possible applications and lines of execution.

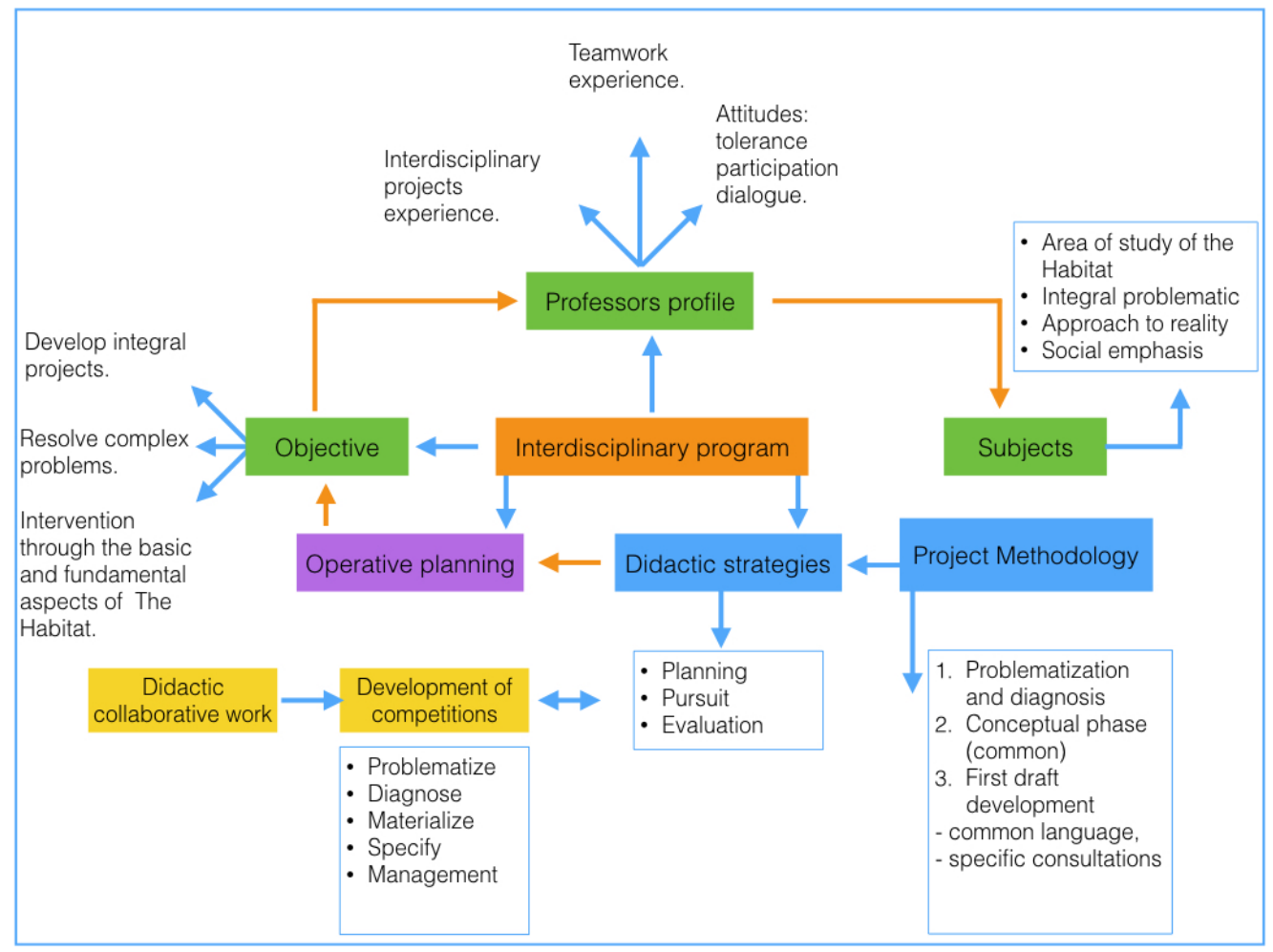

Figure 7. Process design diagram. Source: Faculty of the Habitat. Autonomous University of San Luis Potosi.

\section{Concluding discussion}

When the time came for me to work with larger spaces, I conceived them as gardens, not as sites with objects but as relationships to a whole. I like to think of gardens as sculpturing of space: a beginning, and a groping to another level of sculptural experience and use: a total sculpture space experience beyond individual sculptures (Isamu Noguchi, n./d.).

It is vital to promote collaborative work between disciplines to determinate the social needs and consequently, to come up with viable solutions to problems through an interdisciplinary project. The workshop aims to develop competencies in both students and teachers; the structure and work climate provides the vision of both parties as a team. Once the connection between the academic communities is made, the easier it will be to establish new links with at-risk communities. The constructions of these bonds are particularly resilient when created by students that are members of the localities. We integrate and underline the vision of $\mathrm{D}$. Schön, a practice such as design can be learned, but it cannot be taught through classroom methods. Moreover, when students are helped to learn to design, the interventions are much more prolific for those produce more through tutoring, like in a reflective practicum (Schön, 1987).

The interdisciplinary workshop is the space where practice and reflection take place; it is the space for the institutional model of the Faculty of the Habitat to interact with the complexity of the social context. It is necessary to privilege, the kind of teaching that assures the reflective and critical assimilation of the fundamental ways of thought, like the deductive thought, the experimental or historical thoughts and the 
reflective and critical one that should always be associating them, notes Bourdieu (2007). The students and researchers inside this learning climate, both develop intrinsic cognitive strategies in order to access new consciousness levels. The individual modifies the context through his own behaviour, operating over it by the laws of practice and effect, notes Santoianni (2006).

As an academic community, we have the social responsibility to participate actively in the construction of knowledge, one that can apply and resolve real problems. In order to do so, the inclusion of the at-risk communities in the process design is essential.

Resilience is born and assembled from bonds, from empathising, sharing knowledge and experience. The workshop starts from gaining domain and understanding how to intervene the habitat in a most conscious way through urban and landscape design. In everyday life knowledge appears socially distributed, it is worth saying that different individuals posses different gradations, the social distribution of knowledge of certain elements that constitute daily reality can be extraordinary complex, even confusing for those who watch from outside according to Luckmann (2003).

Universities have regained social credibility, students play a mayor role in the activation of practical use of knowledge our times, the knowledge society relies on the construction of useful a valuable cognitive skills. Resilience through social empowerment is one of the main objectives of educational institutions nowadays. New links between academia and society have to find their way in order to construct an equal and respectful way of cities growth. This process design is just one of many options for building a new way of understanding this phenomenon.

The sense of belonging and the construction of identity is one of the keys to promote different cognitive approaches in search for new ways of conceiving process design by the deep and integral understanding of complexity of the habitat.

The bottom of the foot measures gravity; we trace the density and texture of the ground through our souls. Standing barefoot on a smooth glacial rock by the sea at sunset, and sensing the warmth of the sun-heated stone through one's souls, is an extraordinarily healing experience, making one part of the eternal cycle of nature. One senses the slow breathing of the earth (Pallasmaa, 2012).

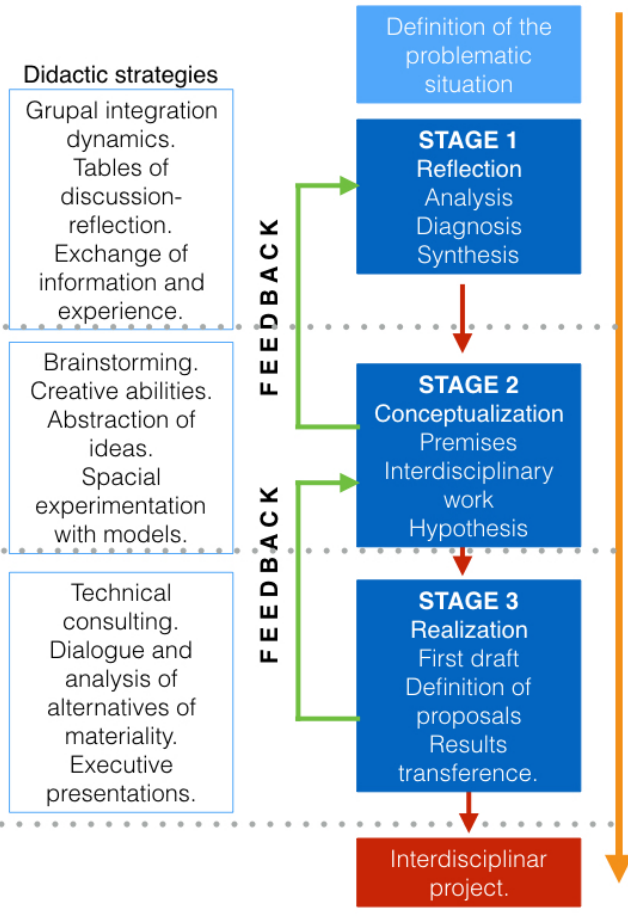

Figure 8. Process design didactic strategies for each stage. Source: Faculty of the Habitat. Autonomous University of San Luis Potosi.

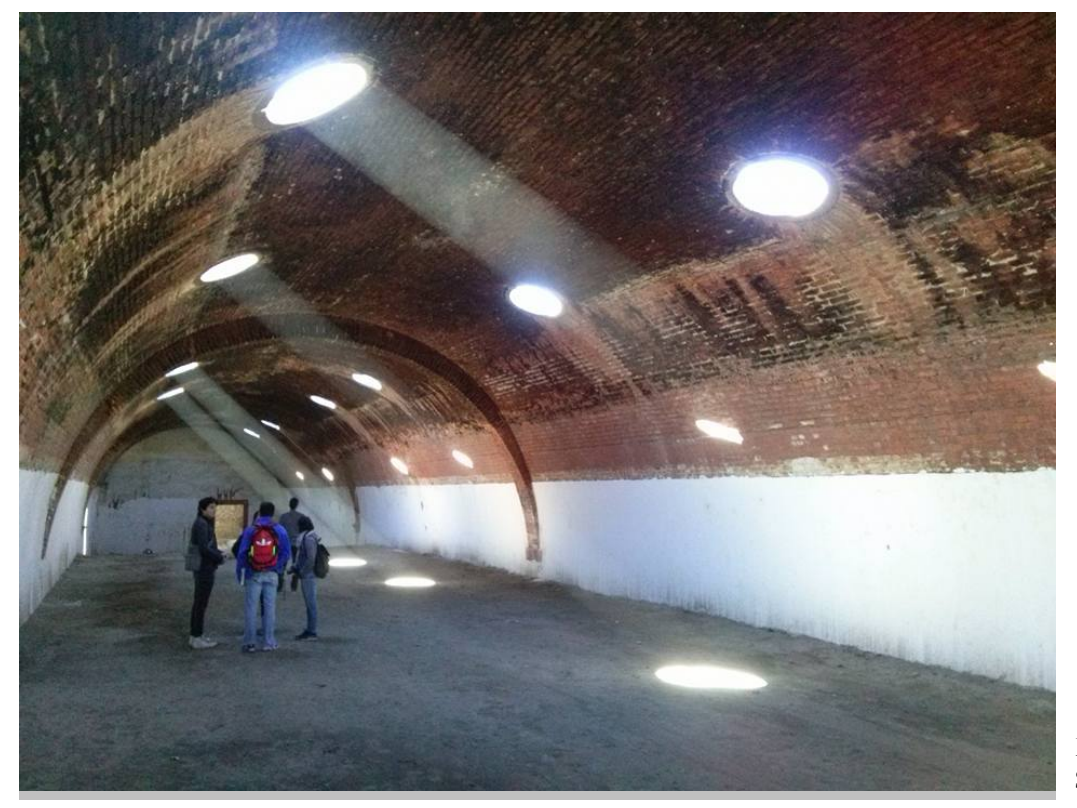

Figure 9. Former storage room of La Sauceda. Source: María Elena Molina Ayala. 


\section{Reierences}

Alexander, C. (1979). The timeless way of buiding. New York : Oxford University Press.

Bauman, Z. (2007). Tiempos líquidos. Vivir en una época de incertidumbre. España : Ensayo Tusquets Editores.

Bourdieu, P. (2007). Capital cultural, escuela y espacio social. España : Siglo XXI editores. 132-146

Litwin, E. (2008). El oficio de enseñar Condiciones y contextos. Buenos Aires : Paidós. 100.

Luckmann, T. (2003). La construcción social de la realidad. Buenos Aires : Amarrortu.

Morin, E. (2011). Hacia dónde va el mundo. México : Paidos.

Pallasmaa, J. (2012). Los ojos de la piel. La arquitectura y los sentidos. México : GG.

Root-Bernstein, R \& M. (1999). Sparks of Genius. The 13 thinking Tools of the world's most creative people. Boston : Houghton Mifflin Company. 317.

Sánchez, R. (2010). Enseñar a investigar. Una didáctica nueva de la investigación en ciencias sociales y bumanas. México : iisue. 136.

Santoianni, F. (2006). Modelos teóricos y metodológicos de la enseñanz̧a. España : Siglo XXI editores.

Schön, D. (1987). La formación de profesionales reflexivos. Hacia un nuevo diseño de la enseñanza y el aprendizaje en las profesiones. Barcelona : Paidós.

Schumacher, P. (2013). I am trying to imagine a radical free-market urbanism. Log, 28, 39-52.

Wenger, E. (2002). Cultivating communities of practice: a guide to managing knowledge. Boston : Harvard Business School Press. 